\title{
Addition of selected ginger extract on total phenolic, antioxidant and sensory properties of the syrup coconut sap (Ginger - SCS)
}

\author{
"Karseno, Setyawati, R., Haryanti, P. and Tri Yanto \\ Department of Agricultural Technology, Jenderal Soedirman University, Purwokerto, Central Java, \\ Indonesia 53122
}

\begin{abstract}
Article history:
Received: 20 December 2020

Received in revised form: 9

February 2021

Accepted: 29 May 2021

Available Online: 31

December 2021

Keywords:

Coconut sap,

Functional drink,

Ginger extract,

Ginger syrup coconut sap

(Ginger-SCS)
\end{abstract}

DOI:

https://doi.org/10.26656/fr.2017.5(6).750

\begin{abstract}
This study aimed to determine the effect of adding selected ginger extract on the total phenolic, antioxidant and sensory properties of its syrup coconut sap (Ginger-SCS). Three selected rhizomes including normal, aromatic, and wild ginger were shredded and extracted with warm water and filtered. The extract was added into coconut sap to obtain the final concentrations of $2.5 \%, 5 \%$, and $7.5 \%(\mathrm{v} / \mathrm{v})$. It was heated to increase the concentration and the coconut sap syrup without ginger extract was used as a control. Furthermore, the total phenolic, antioxidant activity, and sensory properties of GingerSCS were determined. The result showed that the addition of ginger extract has a significant effect on the total phenolic and antioxidant activity of Ginger-SCS. The addition of wild ginger produces Ginger-SCS with the highest total phenolic content. Increasing the concentration increases the total phenolic and antioxidant activity of Ginger -SCS. In addition, 7.5\% wild ginger extract produces Ginger-SCS with a total phenolic of $0.63 \%$ and antioxidant activity of $25.75 \%$, which is higher than other concentrations. The addition of ginger extract resulted in browner colour than the control. Increasing ginger concentration increases the ginger taste and aroma of the product. On the contrary, the addition of ginger extract causes reduced sweetness of the product when compared to the control. Generally, the panellist liked the product with the addition of ginger and aromatic ginger.
\end{abstract}

\section{Introduction}

Coconut sap is obtained by cutting its flower buds and it is rich in sugar $(10 \sim 15 \%)$, contains 16 kinds of amino acids, vitamins, and contains a nearly neutral $\mathrm{pH}$. The sap has a sweet taste, good smell, and is colourless. Generally, it is the raw material used for sugar production and also widely produce coconut sugar production (Purnomo, 2007; Karseno et al., 2018) used as a fresh drink, fermented to produce alcoholic beverages such as toddy, wine, arak, and ethanol (syrup, cake, and powder) production (Hebbar et al., 2018). Sugar is a natural sweetener, flavour and colour enhancer used in various types of traditional cuisine and beverages. It is a well-known tropical plant in Indonesia, Malaysia, India, Thailand, Sri Lanka, Myanmar, and Cambodia (Victor, 2015).

Recently, functional foods or drinks have become more popular with consumers because they contain active components that have a physiological function to prevent disease or achieve optimal health. It is defined as any modified food or ingredient that provides structural, functional, or health benefits promoting optimal health, longevity, or quality of life (Hasler, 2002). Furthermore, it was reported that functional food provides a health benefit beyond basic nutrition (for the intended population). Examples may include conventional; fortified, enriched, or enhanced foods; and dietary supplements. They provide essential nutrients beyond quantities necessary for normal maintenance, growth, and development, and other biologically active components that impart health benefits or desirable physiological effects (Clydesdale, 2004). It is also known as nutraceuticals, highly nutritious, and associated with a number of powerful health benefits.

Ginger is rich in active constituents such as phenolic and terpene compounds (Prasad et al., 2013). It is rich in various chemical constituents, including phenolic compounds, terpenes, polysaccharides, lipids, organic acids, and raw fibres (Mao et al., 2019). In addition, it is a source of natural bioactive compounds, which work powerfully as antioxidants, antimicrobials, anticancer 
cell growth, and many other functions. Ginger (Zingiber oficinale), aromatic (Kaemferia galanga L.), and wild ginger (Curcuma zanthorrhiza) are among the rhizomes containing various bioactive compounds, which are beneficial to the health of the consumer (Tewtrakul et al., 2005; Mao et al., 2019; Srivastava et al., 2019). Ginger (Zingiber officinale Roscoe), which belongs to the Zingiberaceae family and the Zingiber genus, has been commonly consumed as a spice and herbal medicine for a long time (Han et al., 2013). Furthermore, more bioactive compounds have been identified, such as phenolic and terpene. The phenolic compounds are mainly gingerols, shogaols, and paradols, which account for the various bioactivities of ginger (Stoner, 2013). The health benefits of ginger are mainly attributed to its phenolic compounds, such as gingerols and shogaols (Mao et al., 2019). In recent years, ginger has been reported to possess biological activities, such as antioxidant, anti-inflammatory, antimicrobial, and anticancer activities.

Ginger rhizomes can be used in food and drinks due to their spicy and savoury sensation. It is used in a variety of food and beverage applications, providing specific functional properties due to its bioactive compounds (Srinivasan, 2017). Ginger drink is a traditional beverage that became one of the products of interest by consumers (Apriyana et al., 2017). In addition, it is widely used in food processing, such as pickled ginger, biscuits, candy, gingerbread, beer (ginger ale), powder, and syrup (Vasala, 2012). Adding the extract to turmeric white drinks increases antioxidant activity.

The addition of ginger extract to the production of syrup coconut sap (Ginger-SCS) is one method to produce a functional drink. In this study, three types of ginger rhizomes (ginger, aromatic ginger, and wild ginger) were used to produce Ginger-SCS. Generally, functional drinks can be produced using can and coconut sugar as a sweetener in powdered or concentrated form. The use of coconut sap as a sweetener in such products has not been investigated and found in the market. Therefore, this is an innovation and product development in the production of the functional drink. In addition, the determination of the antioxidant activity and sensory properties of the product should be investigated.

This study aimed to determine the effect of three ginger types of the extract on total phenolic, antioxidant activity, and sensory properties of Ginger-SCS. Also, to determine the type of ginger extract that produces Ginger -SCS with the highest total phenolic and antioxidant activity.

\section{Materials and methods}

\subsection{Materials}

The coconut sap was obtained from a local farmer in Banyumas regency, Central Java province. Ginger (Zingiber officinale), aromatic (Kaemferia galanga L.), and wild ginger (Curcuma zanthorrhiza) were obtained from a local market in Purwokerto, Central Java. All chemical reagents were purchased from Sigma and Merck except as mentioned in the text. The equipment used includes pan, stove, plastic bottle, analytical balance, $\mathrm{pH}$ meter, infrared thermometer, refractometer, viscometer, UV-Vis spectrophotometer, and glassware.

\subsection{Preparation of ginger extracts}

Ginger, aromatic, and wild ginger were washed, peeled, shredded, and added warm water $(1: 1.5 \mathrm{w} / \mathrm{v})$, then filtered to obtain gingers extract. It was allowed to stand for $12 \mathrm{hrs}$ to separate the extract with the dregs (starch) precipitate before being used. The extract was kept in the bottle until used.

\subsection{Production of ginger-syrup coconut sap}

A $5,000 \mathrm{~mL}$ of fresh coconut sap was filtered and heated $\left(97^{\circ} \mathrm{C}\right)$ and the amount of each ginger extract was added to obtain the final concentration of 2.5, 5.0, and $7.5 \%(\mathrm{v} / \mathrm{v})$ when the temperature of sap reaches approximately $85^{\circ} \mathrm{C}$. Furthermore, the process continued and stirring was conducted every 15 mins until the temperature was approximately $102^{\circ} \mathrm{C}$ (standard endpoint temperature that used in production syrup). At this point, the process should be stopped and cooled. The $100 \mathrm{~mL}$ of Ginger-SCS was poured into a sterile glass and protected from exposure to light at room temperature.

\subsection{Determination of total phenolic}

The total phenolic content of Ginger-SCS was determined by spectrophotometer (Naczk and Shahidi, 2004). To $0.50 \mathrm{~mL}$ of the sample, $2.5 \mathrm{~mL}$ of $1 / 10$ dilution of Folin-Ciocalteau's reagent and $2 \mathrm{~mL}$ of $\mathrm{Na}_{2} \mathrm{CO}_{3}(7.5 \%, \mathrm{w} / \mathrm{v})$ were added and incubated at $45^{\circ} \mathrm{C}$ for 15 mins. The absorbance was measured at $765 \mathrm{~nm}$ using a UV-Vis spectrophotometer (Shimadzu, model 1800). The results were expressed as milligrams of tannic acid equivalent per gram of dry weight (mg TAE/ $\mathrm{gdw}$ )

\subsection{Determination of antioxidant activity (DPPH radical scavenging activity)}

Antioxidant activity of Ginger-SCS was determined by $\mathrm{DPPH}$ radical scavenging activity (Phongkanpai et al., 2006) with slight modification. The principle involves trapping hydrogen from antioxidants by free 
radicals. DPPH is the free radical source that was reacted with samples containing antioxidants (Prakash et al. 2011). It shows a strong absorption band at $517 \mathrm{~nm}$ due to its odd electron and the solution appears a deep violet colour. The presence of antioxidants resulted in a change in the colour of the solution from violet to pale yellow due to changes of DPPH to DPPH-H (Xu and Hu, 2004). The scavenging activity is shown by the percentage reduction in the intensity of the purple colour of DPPH (Prakash et al., 2011).

The samples were reacted with the stable DPPH radical in an ethanol solution. The reaction mixture consisted of $0.5 \mathrm{~mL}$ of sample, $3 \mathrm{~mL}$ of ethanol, and 0.3 $\mathrm{mL}$ of $0.5 \mathrm{mM}$ DPPH radical. The changes in colour (from deep violet to light yellow) were read at $517 \mathrm{~nm}$ using a UV-ViS spectrophotometer (Shimadzu, model $1800)$. Furthermore, the mixture of ethanol $(3.3 \mathrm{~mL})$ and sample $(0.5 \mathrm{~mL})$ was used as blank. The control solution was prepared by mixing ethanol $(3.5 \mathrm{~mL})$ and DPPH radical solution $(0.3 \mathrm{~mL})$. The scavenging activity percentage $(\%)$ was determined according to the formula below.

Radical DPPH scavenging activity $=\frac{\text { Abs control }- \text { Abs sample }}{\text { Abs control }} \times 100 \%$

\subsection{Sensory analysis}

Twenty trained panellists from the Food Science and Technology Study Program were conducted at the Sensory Analysis Laboratory of Agriculture Technology Department, Jenderal Soedirman University. All the samples were blind coded with 3 digits which differed from each other. The $10 \mathrm{~mL}$ of Ginger-SCS was dissolved in $100 \mathrm{~mL}$ drinking water for the sensory test. Each panellist was served with $50 \mathrm{~mL}$ of syrup solution (for each Ginger-SCS). They were asked to evaluate the five sensory attributes including colour, sweetness, ginger aroma, taste, and preferences (overall acceptability) of the samples. The properties were evaluated by using 4 score scale for each attribute: colour - yellowish brown to dark brown; sweetness - not sweet to very sweet; ginger aroma - not strong to very strong; ginger taste - not strong to very strong; and preferences (overall acceptability) - disklike to very much like. In addition, the individual score for each sample was calculated to achieve the total mean for each sample.

\subsection{Statistical analysis}

Data were expressed as the means of three independent experiments. A one-way ANOVA with Duncan Multiple Range Test was used to evaluate the significance of the results, and the probability $(\mathrm{p})$ value $<0.05$ was considered significant.

\section{Results and discussion}

\subsection{Total phenolic}

Phenolics are aromatic cyclic compounds with one or more hydroxyl $(\mathrm{OH})$ groups that can inhibit the oxidation of lipids by releasing hydrogen atoms into free radicals (Damodaran and Parkin, 2017). Analysis of total phenolic is a basic test to evaluate antioxidant activity since some of these compounds inhibit the oxidation process (Vermerris et al., 2006).

The addition of ginger extract gives a significant effect on total phenolic Ginger-SCS. The effect of ginger, aromatic ginger, and wild ginger on the total phenolic content of Ginger-SCS was $0.47,0.36$, and 0.61 (mg TAE/g) higher than the control at $0.30 \mathrm{mg} \mathrm{TAE} / \mathrm{g}$ (Figure 1).

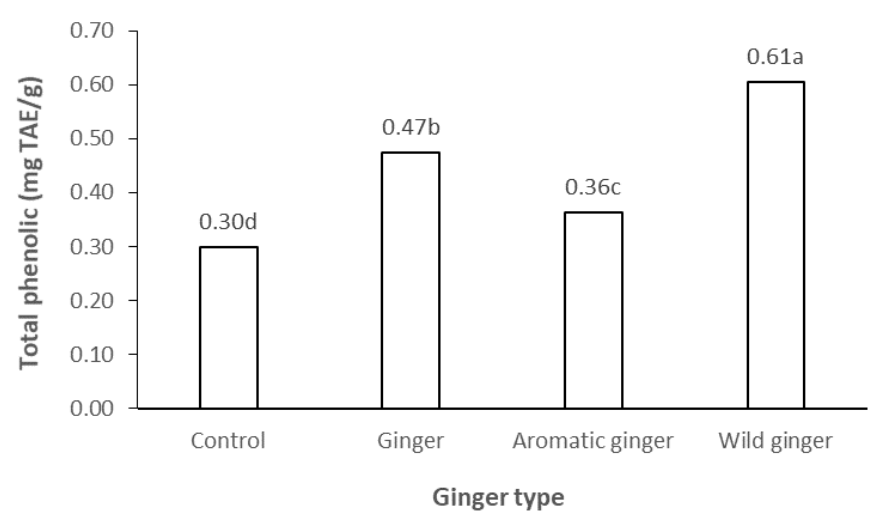

Figure 1. Total phenolic content of Ginger-SCS on three types of ginger extract. Various concentration of the ginger extract was added during sap heating at a temperature of approximately $85^{\circ} \mathrm{C}$. The values followed by the same letter indicate no significant difference $(\mathrm{p}>0.05)$.

Figure 1 shows that the total phenolic with the addition of ginger extract was higher than control (no addition of ginger extract). The highest content resulted from the addition of wild ginger extract, followed by the addition of ginger and aromatic ginger extract. This is consistent with a preliminary experiment that the value of total phenolic in wild ginger extract $(11.79 \%)$ was higher than ginger $(1.27 \%)$ and aromatic ginger $(0.28 \%)$. Phenolic compounds are the dominant phytochemical components in wild ginger extract (Maizura et al., 2011; Mao et al., 2019).

The effect of ginger extract concentration on total phenolic of Ginger-SCS was presented in Figure 2. It was shown that increasing the concentration of all ginger type addition $(2.5 ; 5$; and $7.5 \%$ ) increases the total phenolic content. The Ginger-SCS with the addition of ginger extract in the concentration of $7.5 \%$ shows the highest content of total phenolic $(0.51 \mathrm{mg}$ TAE$/ \mathrm{g})$. The ginger extract concentration of $5 \%$ and $2.5 \%$ were 0.49 and 0.44 (mg TAE/g), respectively. Furthermore, the addition of wild ginger extract in the concentration of 
$7.5 \%$ resulted in the highest total phenolic content $(0.68$ mg TAE/g) of Ginger-SCS (Figure 3).

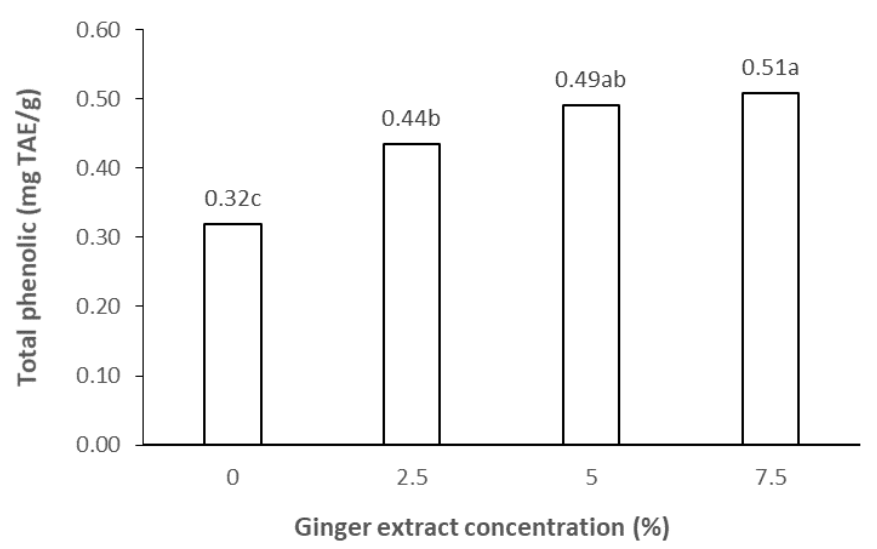

Figure 2. Total phenolic of Ginger-SCS on the various concentration of ginger extract. Three types of ginger extract were added during sap heating at a temperature of approximately $85^{\circ} \mathrm{C}$. The values that followed by the same letter indicate no significant difference $(\mathrm{p}>0.05)$.

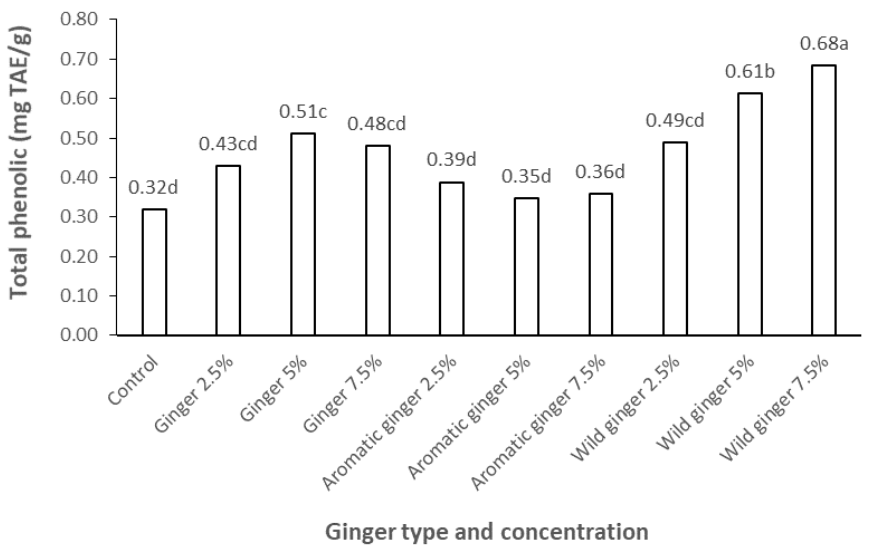

Figure 3. Total phenolic of Ginger-SCSs on various three types ginger extract and concentration. Three types of ginger extract in various concentrations were added during sap heating at a temperature of approximately $85^{\circ} \mathrm{C}$. The values that followed by the same letter indicate no significant difference $(\mathrm{p}>0.05)$.

Total phenolic content was present in essential oils of the ginger rhizome spices. The wild ginger rhizome contains essential oils of $6-10 \%$, aromatic ginger rhizome contains essential oil of $2.4-3.9 \%$, and ginger rhizome contains essential oils of $0.82-1.68 \%$ (Srivastava et al., 2019). Therefore, wild ginger extract addition resulted in the highest total phenolic content in GingerSCS.

\subsection{Antioxidant activity}

The antioxidant activity of Ginger-SCS was determined by the DPPH method. The DPPH $(2,2-$ diphenyl-1-picryl-hydrazyl-hydrate) free radical method is an antioxidant assay based on electron transfer that produces a violet solution in ethanol (Huang et al., 2005). This free radical is stable at room temperature and reduced in the presence of an antioxidant molecule to produce a colourless ethanol solution.
The addition of three types of the ginger extract was significantly affected to antioxidants activity of GingerSCS. Furthermore, the value of the radical scavenging activity with the addition of ginger, aromatic, and the wild ginger extract was $19.41 \%, 15.91 \%$, and $22.36 \%$ higher than the control (10.45\%) (Figure 4). Therefore, the highest antioxidant activity of Ginger-SCS was derived from the addition of wild ginger extract. This was followed by ginger and aromatic ginger extract. Based on a preliminary experiment, it was reported that the antioxidant activity of ginger, aromatic, and wild ginger extracts were $50.26 \%, 21.76 \%$, and $77.41 \%$, respectively. Wild ginger is a source of natural antioxidants since it contains curcuminoids. This element has a higher ability to prevent the formation of peroxides than ginger and aromatic ginger (Mao et al., 2019).

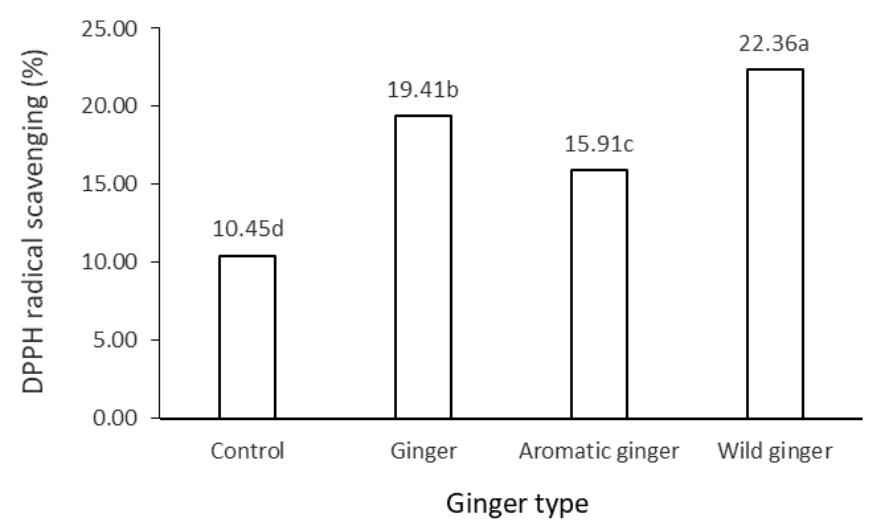

Figure 4. Antioxidant activity of Ginger-SCSs on three types of ginger extract. Three types of ginger extract in various concentrations were added during sap heating at a temperature of approximately $85^{\circ} \mathrm{C}$. The values that followed by the same letter indicate no significant difference $(p>0.05)$.

The effects of the ginger extract concentrations on the antioxidant activity of Ginger-SCS are presented in Figure 5. Addition of the concentration of $2.5 \%, 5 \%$ and $7.5 \%$ on Ginger-SCS resulted in antioxidant activity of $16.94 \%, 19.03 \%$ and $21.71 \%$, higher than control $(10.45 \%)$. Therefore, increased ginger extract concentration increases the antioxidant activity of Ginger

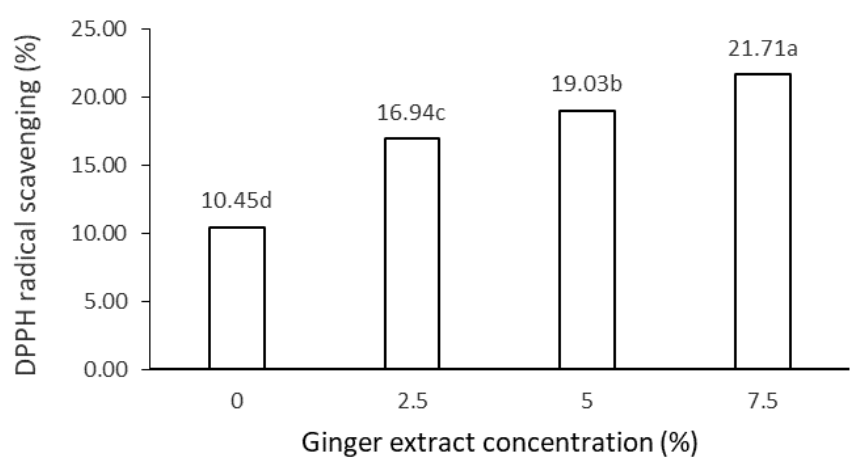

Figure 5. Antioxidant activity of Ginger-SCSs on three types ginger extract concentration. Three types of ginger extract were added during sap heating at a temperature of approximately $85^{\circ} \mathrm{C}$. The values that followed by the same letter indicate no significant difference $(\mathrm{p}>0.05)$. 
-SCS. Furthermore, the addition of wild ginger extract in the concentration of $7.5 \%$ resulted in the antioxidant activity (25.75\%) of Ginger-SCS (Figure 6).

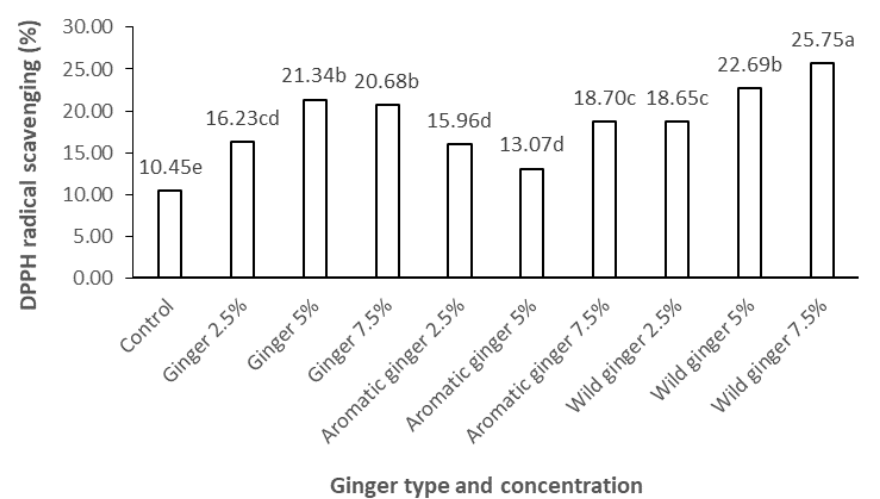

Figure 6. Antioxidant activity of Ginger-SCSs on three types of ginger extract and concentration. Three types of ginger extract in various concentrations were added during sap heating at a temperature of approximately $85^{\circ} \mathrm{C}$. The values that followed by the same letter indicate no significant difference $(\mathrm{p}>0.05)$.

\subsection{Sensory properties}

Five sensory attributes including colour, sweetness, aroma, taste, and preferences (overall acceptability) of Ginger-SCS were evaluated using a 4-line score. Figure 7 shows the result of panellists' response to these attributes.

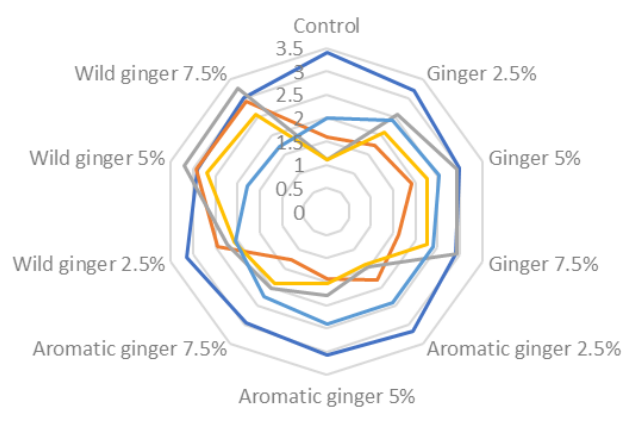

Figure 7. Sensory attributes of Ginger-SCS. The sensory evaluation was performed using a 4-score. Colour - yellowish brown to dark brown; sweetness - not sweet to very sweet; ginger aroma - not strong to very strong; ginger taste - not strong to very strong; and preferences (overall acceptability) disklike to very much like.

Colour is a very important parameter for food because it is seen when the consumer consumes the food. It provides indications of chemical changes that occur in food during heating, such as the formation of brown colour and caramelization (Starowicz and Zieliński, 2019). The colour of Ginger-SCS was performed on the solution form, which was prepared by diluted GingerSCS $(10 \mathrm{~mL})$ with drinking water $(100 \mathrm{~mL})$. Figure 7 showed that the colour score of Ginger-SCS ranges from
$1.32-3.06$ (yellowish-brown to dark brown). In addition to the wild ginger, it shows a higher score than others. Furthermore, increasing the concentration of wild ginger from $2.5 \%$ to $7.5 \%$ increases the colour score from 2.4 to 2.9 (brownies yellow to brown). This is in line with wild ginger which is browner than the other ginger extracts. On contrary, the product without ginger extract (control) shows similar colour to the product with the addition of aromatic and ginger extract were yellowish-brown brown (score 1 to 2 ).

The sweetness score of Ginger-SCS from all ginger extract addition was similar (score 2 to 3 , rather sweet to sweet) and the product with the addition of all ginger extract was lower than control. The sugar without ginger extract (control) showed the highest sweetness score (score 3.5, very sweet). The control does not consist of additional ginger extract because it has a similar taste to the original coconut sugar.

The addition of ginger extract was significantly affected by the aroma of Ginger-SCS and the score was a range from 1.4 to 2.58 (less strong to strong). Ginger has a characteristic odour (Srivastava et al. 2019) because it contains essential oil, zingiberene and zingiberol as the main component. The ginger aroma was derived from volatile compounds such as pinene, camphene, carvone, benzene, eucalyptol, borneol, methyl cinnamate, pentadecane, and ethyl-p-methoxycinnamate (Tewtrakul et al. 2005). Also, the aroma of the product that adds with wild ginger extract show stronger than other ginger extracts.

The addition of ginger extract significantly affected the taste of Ginger-SCS and the score ranged from 1.51 to 2.23 (less strong to moderately strong). Increasing the concentration tends to increase the ginger taste. The addition of $5 \%$ and $7.5 \%$ wild ginger extract resulted in a stronger taste of Ginger-SCS than others. On the contrary, the addition of aromatic ginger shows lower tastes than ginger and wild ginger extract.

The preference level (overall acceptability) is a very important parameter in food because the acceptance of a new product is determined by the level of consumer preferences. This involves a combination of all the parameters that allow the consumer to reach a conclusion. The addition of ginger extract produces Ginger-SCS with a preference score ranging from 1.72 to 2.54 (rather like to like). The addition of aromatic and ginger extract shows a higher preference level compared to wild ginger and control. In contrast, the addition of wild ginger shows the lowest preference score due to the bitter taste of the product. Generally, the product with the addition of ginger and aromatic ginger was liked by the panellist. 


\section{Conclusion}

The addition of ginger extract significantly affected the total phenolic and antioxidant activity of GingerSCS. Increasing the concentration, further increase the total phenolic and antioxidant activity. This study showed that usage of wild ginger extract produces Ginger-SCS with a total phenolic and antioxidant activity higher than ginger and aromatic ginger. The addition of wild ginger extract at $7.5 \%$ produces GingerSCS with total phenolic and antioxidant activity of 0.68 $\mathrm{mg} \mathrm{TAE} / \mathrm{g}$ and $25.75 \%$ higher than others. In the sensory properties, the addition of ginger extract resulted in browner product colour than control. Increasing ginger extract concentration tends to increase the taste and aroma of the product. On the contrary, the addition of ginger extract results in a lower sweetness of the product than control. Generally, the product with ginger and aromatic ginger was liked by the panellist.

\section{Conflict of interest}

The authors declare no conflict of interest.

\section{Acknowledgment}

The author is thankful to the Ministry of Research and Technology of Indonesia and the Rector of Jenderal Soedirman University for the financial support of this study through the scheme Riset Unggulan Unsoed Terapan.

\section{References}

Apriyana, W., Rosyida, V.T., Hayati, S.N., Darsih, C. and Poeloengasih, C.D. (2017). Comparative Study of Powdered Ginger Drink Processed by Different Method: Traditional and using Evaporation Machine. IOP Conference Series: Earth and Environmental Science, 101(1), $012027 . \quad \mathrm{https} / /$ doi.org/10.1088/1755-1315/101/1/012027

Clydesdale, F. (2004). Functional Foods: Opportunities and Challenges. Food Technology Magazine. Retrieved from https://www.ift.org/news-andpublications/food-technology-magazine/issues/2004/ december

Damodaran, S. and Parkin, K.L. (2017). Fennema's Food Chemistry. $5^{\text {th }}$ ed. USA: CRC Press.

Han, Y.A., Song, C.W., Koh, W.S., Yon, G.H., Kim, Y.S., Ryu, S.Y., Kwon, H.J. and Lee, K.H. (2013). Anti-inflammatory effects of the Zingiber officinale Roscoe constituent 12-dehydrogingerdione in lipopolysaccharide-stimulated raw 264.7 cells. Phytotherapy Research, 27(8), 1200-1205. https:// doi.org/10.1002/ptr.4847

Hasler, C.M. (2002). Functional Foods: Benefits, Concerns and Challenges - A Position Paper from the American Council on Science and Health. Journal of Nutrition, 132(12), 3772-81. https:// doi.org/10.1093/jn/132.12.3772

Hebbar, K., Pandiselvam, R., Manikantan, M., Arivalagan, M., Beegum, S. and Chowdappa, P. (2018). Palm sap-Quality profiles, fermentation chemistry, and preservation methods. Sugar Technology, 20, 621-634. https://doi.org/10.1007/ s12355-018-0597-z

Huang, D., Ou, B. and Prior, R.L. (2005). The Chemistry behind Antioxidant Capacity Assays. Journal of Agricultural and Food Chemistry, 53(6), 1841-56. https://doi.org/10.1021/jf030723c

Karseno, Erminawati, Tri Yanto, Setyowati, R. and Haryanti, P. (2018). Effect of $\mathrm{pH}$ and Temperature on Browning Intensity of Coconut Sugar and Its Antioxidant Activity. Food Research, 2(1), 32-38. https://doi.org/10.26656/fr.2017.2(1).175

Maizura, M., Aminah, A. and Wan Aida, W.M. (2011). Total Phenolic Content and Antioxidant Activity of Kesum (Polygonum minus), Ginger (Zingiber officinale), and Turmeric (Curcuma longa) Extract. International Food Research Journal, 18, 529-534.

Mao, Q.Q., Xu, X.Y., Cao, S.Y., Gan, R.Y., Corke, H., Beta, T. and Li, H.B. (2019). Bioactive Compounds and Bioactivities of Ginger (Zingiber officinale Roscoe). Foods, 8(6), 1-21. https://doi.org/10.3390/ foods 8060185

Naczk, M. and Shahidi, F. (2004). Extraction and Analysis of Phenolics in Food. Journal of Chromatography A, 1054(1-2),95-111.

Phongkanpai, V., Benjakul, S. and Tanaka, M. (2006). Effect of $\mathrm{pH}$ on Antioxidative Activity and Other Characteristics of Caramelization Products. Journal of Food Biochemistry, 30(2), 174-86. https:// doi.org/10.1111/j.1745-4514.2006.00053.x

Prakash, D., Upadhyay, G., Pushpangadan, P. and Gupta, C. (2011). Antioxidant and Free Radical Scavenging Activities of Some Fruits. Journal of Complementary and Integrative Medicine, 8(1), 1513. https:// doi.org/10.2202/1553-3840.1513

Prasad, S. and Tyagi, A.K. (2015). Ginger and its constituents: role in prevention and treatment of gastrointestinal cancer. Gastroenterology Research and Practice, 2015, 142979. https:// doi.org/10.1155/2015/142979

Purnomo, H. (2007). Volatile Components of Coconut Fresh Sap, Sap Syrup, and Coconut Sugar. ASEAN Food Journal, 14(14), 45-49. 
Srinivasan, K. (2017). Ginger rhizomes (Zingiber officinale): A spice with multiple health beneficial potentials. Pharma Nutrition, 5(1), 18-28. https:// doi.org/10.1016/j.phanu.2017.01.001

Srivastava, N., Ranjana, Singh, S., Gupta, A.C. Shanker, K., Bawankule, D.U. and Luqman, S. (2019). Aromatic Ginger (Kaempferia galanga L.) Extracts with Ameliorative and Protective Potential as a Functional Food, beyond Its Flavour and Nutritional Benefits. Toxicology Reports, 3(6), 521-28. https:// doi.org/10.1016/j.toxrep.2019.05.014

Starowicz, M. and Zieliński, H. (2019). How Maillard Reaction Influences Sensorial Properties (Colour, Flavour, and Texture) of Food Products? Food Reviews International 35(8), 707-25. https:// doi.org/10.1080/87559129.2019.1600538

Stoner, G.D. (2013). Ginger: Is it ready for prime time? Cancer Prevention Research, 6(4), 257-262. https:// doi.org/10.1158/1940-6207.CAPR-13-0055

Tewtrakul, S., Yuenyongsawad, S., Kummee, S. and Atsawajaruwan, L. (2005). Chemical components and biological activities of volatile oil of Kaempferia galanga Linn. Journal of Science and Technology, 27(2), 503-507.

Vasala, P.A. (2012). Ginger. In Peter, K.V. (Ed.) Handbook of herbs and spices. Vol. 1, p. 195-206. USA: Woodhead Publishing. https:// doi.org/10.1533/9780857095671.319

Vermerris, W. and Nicholson, R. (2006). Phenolic Compound Biochemistry. 1st ed. Netherland: Springer.

Victor, I.R.M. (2015). Processing of Arenga pinnata (palm) sugar. Canada: McGill University SainteAnne-De-Bellevue, PhD Dissertation.

Xu, J. and Hu, Q. (2004). Effect of Foliar Application of Selenium on the Antioxidant Activity of Aqueous and Ethanolic Extracts of Selenium-Enriched Rice. Journal of Agricultural and Food Chemistry, 52(6), 1759-1763. https:// doi.org/10.1021/jf0349836 